\title{
PROPOSTA DE IMPLEMENTAÇÃO DO MARKETING VERDE PARA PRÁTICAS SUSTENTÁVEIS E CONSCIÊNCIA ECOLÓGICA: ESTUDO DE CASO CASA DAS MANGUEIRAS
}

\section{ARTIGO ORIGINAL}

MONTEIRO, Socorro Alencar ', CARVALHO, Thiago Lima 2, OLIVEIRA, Valdeson Melo de ${ }^{3}$, OLIVEIRA, Daniel Barroso de ${ }^{4}$, ROBERTO, José Carlos Alves ${ }^{5}$

MONTEIRO, Socorro Alencar. Et al. Proposta de implementação do marketing verde para práticas sustentáveis e consciência ecológica: Estudo de caso Casa das Mangueiras. Revista Científica Multidisciplinar Núcleo do Conhecimento. Ano 06, Ed. 05, Vol. 07, pp. 116-138. Maio de 2021. ISSN: 2448-0959, Link de acesso: https://www.nucleodoconhecimento.com.br/administracao/marketing-verde, DOI: 10.32749/nucleodoconhecimento.com.br/administracao/marketing-verde

\section{RESUMO}

O presente trabalho tem como objetivo analisar quais as estratégias de responsabilidade social na empresa WF Comércio de Materiais Hidráulicos com foco na logística reversa. Apresenta-se a empresa alternativas para implementação de ações sustentáveis com foco na redução de desperdícios de dejetos sólidos,

\footnotetext{
${ }^{1}$ Graduando (a) do curso de Administração.

${ }^{2}$ Graduando do curso de Administração.

${ }^{3}$ Graduando do curso de Administração.

${ }^{4}$ Coorientador. Bacharel em Administração.

${ }^{5}$ Orientador. Mestrado profissional em Engenharia de produção. Especialização em Gestão em Logística empresarial. Graduação em Administração com Ênfase em Marketing.
}

$\mathrm{RC}: 84984$

Disponível em: https://www.nucleodoconhecimento.com.br/administracao/marketing-verdeb 
consequentemente, minimizando os custos diretos e indiretos em seus produtos e serviços, gerando visibilidade e mais competitividade a organização frente aos seus concorrentes. O marketing verde, proporciona campanhas e ações que objetivam minimizar a degradação e os impactos ambientais. Estando atrelado a logística reversa, torna-se possível a conscientização de funcionários, clientes e da sociedade ao que concerne a sustentabilidade, incentivando assim, a redução do uso de materiais, a reciclagem de resíduos para que ainda sirvam de matéria prima, a reutilização de materiais que estão em perfeito estado de uso, além de estimular hábitos e atitudes mais sustentáveis, logo são ações que passam ser adotadas pela empresa gerando equidade e garantindo melhor qualidade de vida as gerações futuras. Através da pesquisa, detectou-se como área crítica da organização a questão do meio ambiente. No entanto, apresentaram-se ferramentas da Gestão Ambiental como modo de eficácia no processo produtivo, gerando resultados satisfatórios a empresa.

Palavras chave: Marketing Verde, Logística Reversa, Gestão Ambiental, Sustentabilidade, Materiais.

\section{INTRODUÇÃO}

Neste artigo, demonstra-se de forma simples a relação entre logística reversa e Marketing verde na empresa WF Comércio de Materiais Hidráulicos, apontando de que forma esse processo poderá auxiliar a organização, prolongar a vida útil dos seus produtos e peças. Entende-se a logística reversa como ferramenta que pode gerar competitividade e organização, implementando ações sustentáveis que gerem equidade, realizando processos ecologicamente corretos e além de gerar retornos financeiros a empresa, valoriza a sua responsabilidade socioambiental. Ressalta-se que a integração dessas duas áreas, logística reversa e marketing verde, gera economia e destaques à organização frente aos seus concorrentes.

$\mathrm{RC}: 84984$

Disponível em: https://www.nucleodoconhecimento.com.br/administracao/marketing-verdeb 
Considerando-se os impactos causados ao meio ambiente em virtude do descarte de resíduos de forma inadequada, as empresas cada vez mais precisam atentar-se a conscientização e as vantagens da implementação de projetos e ações que visem a preservação do meio ambiente. Diante do problema de pesquisa, faz-se o seguinte questionamento: Como a implementação de uma política de destinação de resíduos pode contribuir com a estratégia de marketing verde?

Neste trabalho pontuam-se os seguintes objetivos específicos, identificar as possibilidades de destinação de resíduos; analisar dentre as possibilidades, quais estratégias de destinação oferecem o melhor custo x benefício, esquematizar um programa robusto e factível de destinação de resíduos sólidos.

Constata-se que apesar de atenderem as demandas concernentes às vendas de varejo, o público alvo da empresa WF Comércio de Materiais Hidráulicos é o Pólo Industrial de Manaus. Por não possuir método ou projeto sustentável de descarte de dejetos sólidos em suas acomodações, a empresa perde parcerias e visibilidade no mercado, desperdiçando materiais que podem gerar redução de custos e lucratividade se reaproveitados de forma correta. Entende-se que é necessário realizar ações para manter o equilíbrio entre as atividades da empresa e o conceito de responsabilidade ambiental, otimizando produtos e processos, investindo cada vez mais em projetos sustentáveis que gerem a preservação dos ecossistemas. Atualmente, os clientes estão cada vez mais esclarecidos e exigentes, na maioria das vezes buscam produtos que não agridam o meio ambiente, grande parte das organizações optam por parcerias que prezem por políticas sustentáveis. No entanto, salienta-se que essa prática de ações voltadas à sustentabilidade vai além de gerar redução de custos e aumentar a lucratividade, o contexto abrange questões mais importantes, como qualidade de vida aos cidadãos e as gerações futuras.

De forma breve, entende-se que esta pesquisa foi dividida em partes: a primeira apresenta desde a formulação e justificativa do problema até possamos chegar ao

RC: 84984

Disponível em: https://www.nucleodoconhecimento.com.br/administracao/marketing-verdeb 
referencial teórico onde, quais serão apresentados os conceitos, importância, tipos e ferramentas da temática utilizada. A segunda apresenta a metodologia onde serão apresentados os procedimentos e a caracterização do objeto de pesquisa (WF Comércio de Materiais Hidráulicos) e a terceira parte, dispõe técnicas e procedimentos de coleta e dados a serem utilizadas para a aplicação do trabalho. Por conseguinte, todas as referências utilizadas para o desenvolvimento do trabalho.

\section{FUNDAMENTAÇÃO TEÓRICA}

O presente artigo busca fundamentar questões voltadas para a logística reversa, marketing verde e sociedade de consumo dentro da organização visando equilibrar o consumo da sociedade com o mínimo impacto ao meio ambiente.

Segundo Liborio (2015, p. 40) "refere-se a parte do desenvolvimento propriamente dito, em que o autor expõe as afirmações de outros teóricos e pesquisas relacionadas ao tema, discutindo-as conforme a perspectivas do seu próprio trabalho".

Para esta pesquisa, utilizou-se de método qualitativo e os instrumentos de coleta de dados foram os artigos científicos analisados por especialistas e resgatados a partir de bases de dados, fornecidas pelo Centro Universitário ou de livre acesso disponíveis.

\subsection{CONCEITOS E DEFINIÇÕES DE LOGÍSTICA REVERSA}

A logística reversa é um conjunto de procedimentos e meios para recolher e dar encaminhamento pós-venda ou pós-consumo a rede empresarial, para reaproveitamento ou destinação correta de resíduos. A CSCMP (2012) traz uma definição mais atualizada da Logística ao apontar que a mesma é um processo importante, que objetiva planejar, implementar e controlar, de uma forma mais efetiva, o fluxo e o armazenamento dos produtos.

RC: 84984

Disponível em: https://www.nucleodoconhecimento.com.br/administracao/marketing-verdeb 
Em 2010 foi promulgada a Lei oㅜ 12.305/10, que define a Política Nacional de Resíduos Sólidos, definiu três diferentes formas de estruturar a Logística Reversa são elas: Regulamento, Acordo Setorial e Termo de Compromisso. Política essa que trouxe como objetivo principal, a reciclagem dos resíduos sólidos, a lei passou a vigorar a partir de 2014, sendo um mecanismo para o desenvolvimento sustentável do planeta, uma vez que possibilita a reutilização e redução das matérias-primas utilizadas.

De acordo com Coltro e Duarte (2013, p. 134) existem duas razões pelas quais se tornam mais difíceis o processo de reciclagem através de logística reversa no nosso país, sendo eles, "[...] falta de informação no mercado brasileiro sobre o tipo de resina que compõe a embalagem plástica, ou seja, ausência do símbolo de identificação; e falta informação sobre o símbolo correto de identificação do material da embalagem."

\subsubsection{IMPORTÂNCIA DE LOGÍSTICA REVERSA}

É um processo tão essencial, mas ainda pouco difundido nas empresas, recolhe e reutiliza os resíduos do processo produtivo e devolve-os para reaproveitamento. Além de gerar bons resultados para as organizações e resultar em benefícios ao meio ambiente e à coletividade, a logística reversa pode ainda ser um diferencial nas ações do marketing que ajudem na difusão de pontos de descarte melhorando a imagem da empresa perante aos clientes e a sociedade como um todo.

Todavia, Oliveira Neto et al. (2014) destacam que para se desenvolver e poder gerar benefícios, a logística reversa precisa ser estimulada, de preferência, por meio de incentivos governamentais, mas principalmente as organizações devem se conscientizar de sua importância, pois à medida que sua utilização aumenta entre as empresas, os fluxos passam a ser mais eficientes.

RC: 84984

Disponível em: https://www.nucleodoconhecimento.com.br/administracao/marketing-verdeb 


\subsubsection{ASPECTOS AMBIENTAIS DA LOGÍSTICA REVERSA}

Segundo Galbiati (2012, p. 2)

...na gestão dos resíduos sólidos, a sustentabilidade ambiental e social se constrói a partir de modelos e sistemas integrados, que possibilitem tanto a redução do lixo gerado pela população, como a reutilização de materiais descartados e a reciclagem dos materiais que possam servir de matéria prima para a indústria, diminuindo o desperdício e gerando renda.

De acordo com o Panorama dos Resíduos Sólidos no Brasil "O montante coletado em 2017 foi de 71,6 milhões de toneladas, registrando um índice de cobertura de coleta de $91,2 \%$ para o país, o que evidencia que 6,9 milhões de toneladas de resíduos não foram objeto de coleta $e$, consequentemente, tiveram destino impróprio." (ABRELPE, 2017, s/p.).

A logística reversa entra na parte de tentar gerenciar melhorias gradativas, principalmente voltadas ao impacto ambiental. A aplicação dela é uma maneira de se posicionar de forma mais sustentável e consciente no mercado e esse instrumento diminui as externalidades negativas e promove uma economia mais regenerativa.

\subsubsection{PROCESSO DE LOGÍSTICA REVERSA A PARTIR DO CICLO DE VIDA DOS PRODUTOS}

Do ponto de vista ambiental, esta é uma forma de avaliar qual o impacto que um produto tem sobre o meio ambiente durante toda a sua vida isso é fundamental para planejar a utilização dos recursos na aplicação de cada etapa do ciclo de vida do produto. O processo da logística reversa vem ganhando espaço nas organizações tornando-se um diferencial competitivo para as empresas a partir do ciclo de vida, responsabilidade do manejo dos resíduos, visando minimizar volume e reduzir os

RC: 84984

Disponível em: https://www.nucleodoconhecimento.com.br/administracao/marketing-verdeb 
impactos causados à saúde humana e à qualidade ambiental e devem ser compartilhados entre fabricantes até o consumidor.

Há uma preocupação da sociedade em relação a gerações futuras, pois reconhecendo o problema ambiental passa por tomar consciência do impacto ambiental. Belink e Mattar (2013, p. 31),

a partir desses e de outros dados da pesquisa, conclui-se que a sociedade brasileira começa a tomar consciência de que, uma vez atingidas às necessidades básicas para o bem- estar, o caminho deve seguir pela via do sustentável e não do consumismo desenfreado.

Os benefícios desta ação se dão pela diminuição de custos com o depósito final do lixo e degradação de áreas que contenham lixo mal acondicionado. Essa ação aumenta a vida útil dos aterros sanitários, reduz a limpeza pública e promove à população uma maior educação e conscientização sobre o meio ambiente, o que suscita ao Estado a necessidade de uma intervenção social com melhorias voltadas ao meio ambiente e a saúde pública (VILHENA, 2013).

\subsection{CONCEITOS E DEFINIÇÕES DE MARKETING VERDE}

"O marketing ambiental, também conhecido como marketing ecológico ou verde, tem como essência a disponibilização de produtos ou de serviços com atrativos ligados ao baixo impacto ambiental" (TAVARES e FERREIRA, 2012, p. 2). Trata-se de uma ação sustentável que passou a ser adotada pelas empresas que a cada dia estão mais comprometidas com a preservação do meio ambiente.

\subsubsection{IMPORTÂNCIA DO MARKETING VERDE E QUESTÃO AMBIENTAL}

"As empresas com práticas sustentáveis são capazes de motivar e aproximar os clientes para si” afirma Junior (2017, p. 4). Ao considerar-se a temática concernente RC: 84984

Disponível em: https://www.nucleodoconhecimento.com.br/administracao/marketing-verdeb 
ao marketing verde, é praticamente impossível identificar fatores negativos com a sua utilização, existem vários benefícios às organizações que adotam tais métodos. O marketing verde é realidade, tornou-se tema de destaque dentre as organizações por ser uma ferramenta eficiente que permite a empresa ganhar espaço.

\subsubsection{MARKETING VERDE COMO FATOR DE COMPETITIVIDADE NO VAREJO}

Atualmente, a maioria dos clientes seja este o consumidor de vendas de varejo ou indústrias, está consciente com meio ambiente. Complementa Guindani (2012, p. 12) no contexto atual, "a visão dos novos consumidores está voltada para a compra de produtos diferenciados, se preocupando como as empresas trabalham em prol ao ambiente e não havendo interesse nos preços, e sim na qualidade do descarte."

É notório que as empresas comprometidas com ações ecologicamente corretas e sustentáveis, tendem a agregar valor aos seus produtos. Com a sociedade tendo maior preocupação com a qualidade de vida, consequentemente a questão ambiental difunde rapidamente, os consumidores estão mais preocupados ao que tange a qualidade e a origem dos insumos utilizados na fabricação dos produtos que estão no mercado procuram cobrar das organizações valores éticos e sustentáveis.

\subsubsection{MARKETING VERDE E LOGÍSTICA REVERSA: DIFERENÇAS E SIMILARIDADES}

Segundo Santos (2012, p. 87) "o termo logística reversa refere-se acerca de que o lucro e meio ambiente funcionem conjuntamente, tanto nos procedimentos ambientais quanto nas apurações financeiras positivas da empresa, com isto, entende-se o objetivo principal a logística reversa." O marketing verde é utilizado pelas organizações para gerar diminuição dos custos operacionais dos produtos

RC: 84984

Disponível em: https://www.nucleodoconhecimento.com.br/administracao/marketing-verdeb 
e/ou serviços que a organização oferece. A logística reversa é a área da logística que trata dos aspectos de retornos de produtos, embalagens ou materiais ao seu centro produtivo. Ou seja, a empresa que implanta a logística reversa, consequentemente cumpre as ações de marketing verde simultaneamente, visto que esta objetiva aumentar a vida útil dos produtos ou dos materiais que os compõe, através do uso metodológico dos $4 \mathrm{rs}$ da sustentabilidade, que tem por definição reutilizar, remodelar, reciclar, recondicionar e descartar.

\subsubsection{AS VANTAGENS DO MARKETING VERDE}

Segundo Moore (2013, p. 10), “o Branding verde é um composto de práticas relacionadas à estratégia de uma organização para otimizar valor a marca através de um diferencial competitivo, voltado a construção da força da marca."

Uma das principais vantagens do marketing verde é o aumento da credibilidade sobre a marca da empresa. A estratégia do marketing verde vincula os produtos ou serviços da organização a uma visão ecológica e socialmente consciente. Para usala é necessário conscientizar seus clientes das vantagens de se adquirir seus produtos e serviços, dando-Ihes certeza de que são praticados dentro da empresa atitudes de proteção ambiental, como a gestão de resíduos correta e eficiente. $\mathrm{O}$ marketing verde é extremamente importante, pois possibilita a organização a ter reputação mais valiosa perante o mercado, facilita a aceitação internacional, pois tem um alcance de público mais elevado, tem perspectivas de longo prazo e ampliação de lucros, gera eficiência no uso de matérias e serviços, aperfeiçoa processos, diminui os custos e gera educação ambiental.

\subsubsection{MARKETING VERDE E MARCAS}

Mesmo ainda não podendo assumir o papel principal de ferramenta de diferenciação competitiva, o marketing verde é avaliado como um dos principais instrumentos de

RC: 84984

Disponível em: https://www.nucleodoconhecimento.com.br/administracao/marketing-verdeb 
ganho de visibilidade de uma marca (BANERJEE, 2012). Considerando-se todos os benefícios da implementação do marketing verde, várias empresas adotaram essa ferramenta nos seus processos visando lucratividade, reconhecimento, vantagens competitivas e o alcance de clientes, afinal pessoas satisfeitas com a postura da empresa, começam a recomendá-la para outras pessoas que também são ecologicamente corretas. O Brasil é considerado uma das maiores economias verdes do mundo, podemos destacar algumas empresas que fazem parte deste contexto: Natura, Banco do Brasil, Toyota, Fiat, Walmart dentre outras.

\subsection{SOCIEDADE DE CONSUMO}

A sociedade de consumo é um termo bastante utilizado para representar os avanços de produção do sistema capitalista e caracteriza-se, antes de tudo, pelo desejo socialmente expandido da aquisição "do supérfluo", do excedente, do luxo. O consumismo é uma conduta de caráter impulsivo, em que Moura (2021) define como o ato de comprar coisas fúteis excessivamente por impulso ou por desejo de comprar. Tal comportamento é tido como algo destrutivo que causa impacto nos diversos aspectos da vida cotidiana.

Temos uma sociedade de consumo que incita os desejos para não os realizar, uma vez que isso enfraqueceria sua força de produção de mercadorias que, por sua vez, ocorre em grande quantidade e é rapidamente transformada em lixo, o qual ocupa todos os espaços possíveis de socialização.

\subsubsection{COMPORTAMENTOS DO CONSUMIDOR}

Os autores Churchill e Peter (2015) tem como consumidores aqueles que compram bens e serviços para utilidade própria ou para outras pessoas, sem a intenção de revendê-los ou utilizá-los como insumos. Ademais, os autores acrescentam que ao longo do processo de criação de valor do produto/serviço perante o consumidor e de

RC: 84984

Disponível em: https://www.nucleodoconhecimento.com.br/administracao/marketing-verdeb 
geração de lucro para as empresas que produzem esses bens/serviços, é importantíssimo que os profissionais de marketing conheçam a escolha do consumidor quanto a determinados tipos de bens/serviços, disponíveis no mercado.

Tendo o conhecimento destes fatores, é possível que as empresas elaborem estratégias voltadas à segmentação dos mercados e realizem uma análise comportamental do consumidor, em determinados segmentos de mercado. Assim, através da análise do mercado e a partir das características de consumo dos clientes, as empresas podem desenvolver novos produtos e/ou serviços que condizem com as necessidades de cada tipo de consumidor, ou a cada grupo de consumo (LAS CASAS, 2013).

\subsubsection{PROCESSOS DE DECISÃO DE COMPRA}

Garcia (2012) afirma que a efetuação da compra se dá pela tomada de decisão baseada no pensamento, comportamento e sentimento daquele que deseja comprar. Sendo assim, é imprescindível que a empresa entenda esses aspectos associados à decisão de compra do consumidor, a fim de definir estratégias de atuação no mercado.

\subsubsection{CONSUMIDOR VERDE E PREOCUPAÇÃO AMBIENTAL}

Diversas organizações do mundo corporativo estão procurando alterar o caminho atual da degradação ambiental pela qual o planeta vem sofrendo, tendo como base um processo denominado "revolução verde".

Para Fiorillo (2013), o consumo passa a ser sustentável quando há uma preocupação quanto à produção e escolha de produtos que não extraiam recursos naturais e que posteriormente possam ser reaproveitados para outras finalidades. Dessa forma, o produtor e o consumidor devem considerar as consequências ambientais durante a sua escolha.

RC: 84984

Disponível em: https://www.nucleodoconhecimento.com.br/administracao/marketing-verdeb 


\subsubsection{ISO 14001}

A ISO (Organização internacional para Normalização), é uma federação mundial de entidades nacionais de normalização (organização não governamental), representando praticamente $95 \%$ da produção industrial do mundo.

Produção ou manufatura limpa, padrões e instruções operacionais, além de sistemas de controle representam algumas ferramentas que contemplam tal organização. Sendo assim, a configuração estruturada destas ferramentas foi denominada de Sistema de Gestão Ambiental (SGA) é um dos meios atualmente mais utilizados pelas organizações para obtenção e consecução de tal sistema é a norma ISO 14001 (ÁVILA e PAIVA, 2016).

Para que a certificação ISO 14001: 2015 seja alcançada, um processo de cinco etapas deve ser realizado. Esse processo envolve a solicitação do registro, a verificação da documentação do SGA, uma revisão preliminar do local, a auditoria de certificação e a determinação da certificação. Sendo assim, a implantação do SGA não depende de uma futura certificação. Ela envolve etapas de implantação maiores que as da certificação e todas elas objetivam tal certificação. Essas etapas compreende o compromisso e a colaboração de todos funcionários com a empresa, a avaliação das práticas e dos procedimentos ambientais que já existem; o planejamento da migração para o novo sistema; e a implementação do mesmo (BISPO e CAZARINI, 2016).

\section{MATERIAIS E MÉTODOS}

Os materiais e métodos abordados nesta pesquisa a partir de um estudo de campo na empresa casa das mangueiras possibilitou analisar e coletar informações para aprimorar o trabalho com base na metodologia.

RC: 84984

Disponível em: https://www.nucleodoconhecimento.com.br/administracao/marketing-verdeb 
Trigueiro (2014, p. 30) afirma que "Metodologia tem diferentes significados e, sendo assim, pode ser empregado em diferentes contextos. O método e a técnica de pesquisa que melhor se adéqua ao objetivo que ele pretende alcançar com a realização do estudo."

Ao aproveitar as disciplinas que orientam a produção de um trabalho científico, o aluno desenvolve maturidade acadêmica, a fim de compreender os métodos e as técnicas como ferramentas e meios para a construção não só de um trabalho, mas de uma pessoa crítica, reflexiva e pesquisadora.

\subsection{PROCEDIMENTOS METODOLÓGICOS}

O presente trabalho iniciou-se por meio de pesquisas bibliográficas e coletas de dados, tendo como objetivo de identificar artigos, livros sobre o tema referenciado. Mediante disso este trabalho utilizará ferramentas sempre em busca de satisfazer os potenciais clientes, implementar processos e rotinas eficientes para solucionar o problema apontado na empresa.

\subsubsection{QUANTO À NATUREZA}

A pesquisa será de natureza qualitativa e aplicada. Zanella (2013, p. 95) afirma que a pesquisa qualitativa é "particularmente útil como ferramenta para determinar o que é importante para os clientes e por que é importante, e não para saber quantos clientes avaliam positivamente ou não um determinado produto ou serviço."

A pesquisa baseou-se em pesquisa qualitativa com base nos dados coletados e em desenvolver a ferramenta escolhida de acordo com o tema em questão solucionando a problemática na organização e aplicada que será possível aplicar o instrumento de estudo na organização estudada.

RC: 84984

Disponível em: https://www.nucleodoconhecimento.com.br/administracao/marketing-verdeb 


\subsubsection{QUANTO AOS FINS}

Em se tratando dos fins, realizou-se pesquisa exploratória e descritiva. Vergara (2016 p. 74) afirma que a "pesquisa descritiva expõe características de determinada população ou de determinado fenômeno. Pode também estabelecer correlações entre variáveis e definir sua natureza."

Quanto aos fins para elaboração do artigo foi utilizada a pesquisa descritiva usando técnicas padronizadas de coleta de dados como questionário e observação sistemática e exploratória em que realizou através de entrevista com os gestores da empresa casa das mangueiras resultando na hipótese de implementação do marketing verde na organização devido os matérias sem uso serem descartados sem ações de reciclagem coletando informações dos colaboradores sobre o descarte todos incentivaram a implementação objetivando os impactos ambientais.

\subsubsection{QUANTO AOS MEIOS}

Segundo Pereira (2014, p. 74) afirma que estudo de caso se "torna interessante ao estudante ou autor interessado em utilizar a metodologia do estudo de caso que faça a descrição e análise do caso de modo mais detalhado possível."

Quanto aos meios, adotou-se estudo de caso a fim de tornar perceptíveis as informações, coletas e pesquisa bibliográfica para suporte e reforço teórico de análise das pesquisas capaz de proporcionar melhor embasamento sobre o tema debatido com informações coletadas junto aos sócios para a construção do artigo científico.

\subsection{CARACTERIZAÇÃO DA EMPRESA: CASA DAS MANGUEIRAS}

A Casa das Mangueiras, empresa de pequeno porte está localizada na Av. Autaz Mirim, número 2872, Armando Mendes, CEP 69090-000 zona leste da cidade de RC: 84984

Disponível em: https://www.nucleodoconhecimento.com.br/administracao/marketing-verdeb 
Manaus, está em atividade desde janeiro de 2011, sendo uma referência entre as empresas que atuam no segmento de conexões e mangueiras de Manaus e Amazonas. Comercializam uma ampla variedade de produtos para diversos setores de atividades industrial e agroindustrial, formando boas parcerias através de muita dedicação, profissionalismo e excelência no atendimento.

Atualmente os produtos apresentados ao público são Mangueiras hidráulicas para máquinas e automotores hidráulicos, Mangueiras industriais, Tubos pneumáticos, Mangotes, Terminais hidráulicos e adaptadores hidráulicos e serviços de entrega de materiais, visita técnica para diagnóstico e atendimento 24 horas para clientes parceiros, ou seja, clientes que são cadastrados na Empresa.

\section{RESULTADOS E DISCURSÕES}

Com base em estudo realizado na Casa das mangueiras foi constatado que a empresa possui aspectos relevantes nas áreas funcionais e observou-se que Marketing é a área considerada mais crítica conforme gráfico e quadro seguido das ações interventivas para melhoria do problema proposto que é: Como a implementação de uma política de destinação de resíduos sólidos pode contribuir com a estratégia de marketing verde?

A medição de desempenho das áreas críticas na empresa casa das mangueiras como o Marketing, produção e operações, finanças, recursos humanos, administração e logística tem por objetivo buscar a menor média nos setores e a importância de cada uma delas a partir daí adotar as medidas necessárias para organização seguir com planejamento das inconformidades na empresa. Esse é um dos primeiros passos da empresa entender o ambiente mais ao seu redor com essa atitude melhorar os processos de forma a se adequar com o que o público externo exige, buscando identificar as principais competências da equipe e quais ainda precisam ser identificadas.

RC: 84984

Disponível em: https://www.nucleodoconhecimento.com.br/administracao/marketing-verdeb 


\subsection{GRÁFICO DAS ÁREAS MAIS CRÍTICAS}

Gráfico : Média do Desempenho por área funcional

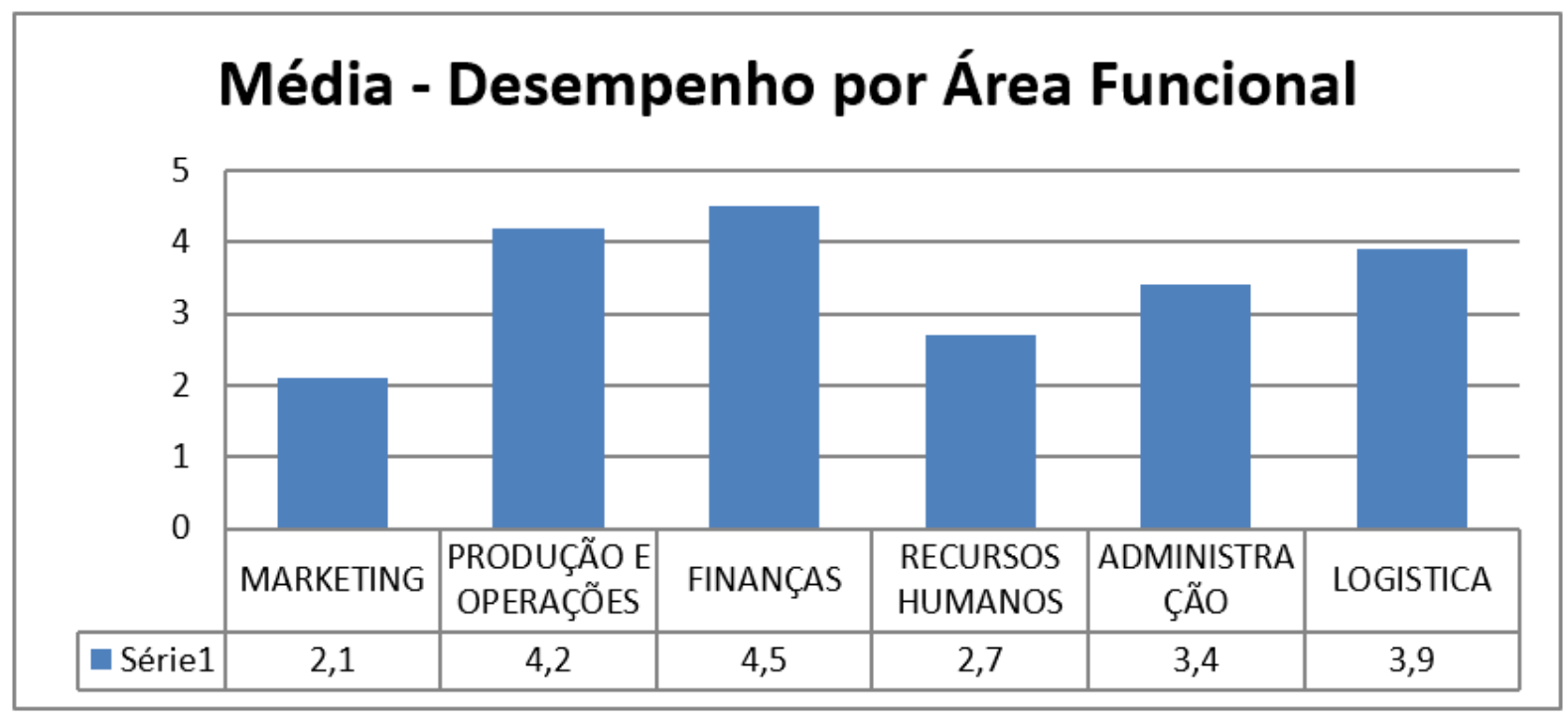

Fonte: Realizado pelos autores, 2021.

Nota- se que empresa tem melhor nível de desempenho de forma clara na área de finanças e em produção, já na área de recursos humanos, administração e logística tem desempenho médio e na área a ser implementada com a proposta será marketing com baixo desempenho de 2,1. O presente artigo tem como foco principal trabalhar de forma incessante nesta área mais crítica no processo da implementação do marketing verde para conscientizar seus clientes e colaboradores das atitudes de proteção ambiental, como a gestão de resíduos correta e eficiente.

\subsection{QUADRO DA ÁREA MAIS CRÍTICA}

Segundo Maximiano (2012), examinar as competências que destacam a empresa perante seus concorrentes, focar nos problemas em áreas funcionais como recursos humanos, operações e marketing, por exemplo, e ainda permite a comparação com outras empresas e com melhores práticas de mercado a serem desenvolvidas.

$\mathrm{RC}: 84984$

Disponível em: https://www.nucleodoconhecimento.com.br/administracao/marketing-verdeb 
Considerando a área de marketing mais crítica esta leva inevitavelmente a mais investimento de tecnologia focada em marketing que visem à recuperação resíduos, desde que tenha sido comprovada sua viabilidade ambiental. É de grande importância, pois preserva o meio ambiente, eliminam práticas nocivas à saúde, gera retorno financeiro para empresa, tais preocupações se caracterizam pela urgente necessidade de diminuirmos os danos da sociedade ao ecossistema.

Quadro : Área Funcional de Marketing

\begin{tabular}{|c|c|c|c|c|c|c|}
\hline \multicolumn{2}{|c|}{ AREA FUNCIONAL } & \multicolumn{5}{|c|}{ NIVEL OU GRAU DE AVALIAÇÃO } \\
\hline \multicolumn{2}{|c|}{ MARKETING } & $\begin{array}{l}\text { Ponto } \\
\text { muito } \\
\text { forte } 5\end{array}$ & $\begin{array}{l}\text { Ponto } \\
\text { forte } 4\end{array}$ & $\begin{array}{l}\text { Ponto } \\
\text { médio } 3\end{array}$ & $\begin{array}{l}\text { Ponto } \\
\text { fraco }\end{array}$ & $\begin{array}{l}\text { Ponto } \\
\text { muito } \\
\text { fraco } 1\end{array}$ \\
\hline 1 & $\begin{array}{l}\text { A empresa preocupa-se } \\
\text { com as práticas do } \\
\text { marketing verde }\end{array}$ & & & & & $x$ \\
\hline 2 & $\begin{array}{lr}\text { Espaço disponível para } \\
\text { armazenamento } & \text { dos } \\
\text { produtos } & \end{array}$ & & & $x$ & & \\
\hline 3 & $\begin{array}{l}\text { Estratégias de divulgação } \\
\text { referente } \\
\text { sustentabilidade }\end{array}$ & & & & & $x$ \\
\hline 4 & $\begin{array}{l}\text { Plano de gerenciamento } \\
\text { de resíduos }\end{array}$ & & & & & $x$ \\
\hline 5 & $\begin{array}{l}\text { A empresa busca } \\
\text { satisfazer seus clientes }\end{array}$ & & $x$ & & & \\
\hline 6 & $\begin{array}{lrr}\text { Localização } & \text { da } & \text { empresa } \\
\text { favorece } & & 0\end{array}$ & & & & & $x$ \\
\hline
\end{tabular}

RC: 84984

Disponível em: https://www.nucleodoconhecimento.com.br/administracao/marketing-verdeb 


\begin{tabular}{|c|c|c|c|c|c|c|}
\hline & $\begin{array}{l}\text { desenvolvimento das } \\
\text { finanças }\end{array}$ & & & & & \\
\hline 7 & $\begin{array}{l}\text { Fidelização de clientes } \\
\text { quanto aos produtos e } \\
\text { serviços }\end{array}$ & $x$ & & & & \\
\hline 8 & $\begin{array}{l}\text { A empresa possui } \\
\text { conhecimento no mercado } \\
\text { competitivo }\end{array}$ & & & & & \\
\hline 9 & $\begin{array}{lc}\text { Flexibilidade } & \text { nas } \\
\text { negociações } & \text { com } \\
\text { fornecedores } & \end{array}$ & & $x$ & & & \\
\hline \multirow[t]{2}{*}{10} & $\begin{array}{l}\text { Política voltada ao } \\
\text { descarte das mangueiras }\end{array}$ & & & & & $x$ \\
\hline & & 5 & 8 & 3 & 0 & 5 \\
\hline \multicolumn{2}{|c|}{$\begin{array}{l}\text { MÉDIA POR GRAU (POR } \\
\text { COLUNA) }\end{array}$} & 0,5 & 0,8 & 0,3 & 0 & 0,5 \\
\hline \multicolumn{2}{|c|}{$\begin{array}{l}\text { DESEMPENHO DA ÁREA ( } \Sigma) \\
\text { TOTAL }\end{array}$} & \multicolumn{5}{|l|}{2,1} \\
\hline
\end{tabular}

Fonte: Realizado pelos autores da pesquisa, 2021.

\subsection{PLANEJAMENTO DE AÇÕES}

O planejamento de ações é uma ferramenta considerada mais eficiente e simples que consiste em um planejamento de trabalho. Em suma, para a aplicação correta do método $5 \mathrm{~W} 2 \mathrm{H}$, é necessário considerar previamente um plano estratégico de respostas para os problemas a resolver.

Planejar é ação de pensar e registrar o que deve ser feito com continuidade das operações, pois essa ação busca influenciar o futuro e, se colocados em prática, a RC: 84984

Disponível em: https://www.nucleodoconhecimento.com.br/administracao/marketing-verdeb 
empresa terá uma situação favorável, objetivando de projeções futuras para o negócio. (RITTA, 2013).

Esta ferramenta é amplamente utilizada devido à sua compreensão e facilidade de utilização e consistem em responder as sete perguntas de modo que todos os aspectos básicos e essenciais de um planejamento sejam analisados através de respostas simples e objetivas, permite que as informações extremamente cruciais para a contextualização de um planejamento.

Quadro- Ações Interventivas

\begin{tabular}{|c|c|c|c|c|}
\hline ITEM & AÇÕES INTERVENTIVAS & CRONOLOGIA & DURAÇÃO & CUSTO \\
\hline 1 & $\begin{array}{l}\text { Estruturar as políticas de } \\
\text { destinação de inservíveis } \\
\text { mangueiras e conexões usadas }\end{array}$ & $\mathrm{abr} / 21$ & 15 dias & $\begin{array}{l}R \$ \\
2.000,00\end{array}$ \\
\hline 2 & $\begin{array}{l}\text { Definir estratégias de logística } \\
\text { reversa para envio dos produtos } \\
\text { inservíveis }\end{array}$ & mai/21 & 20 dias & $\begin{array}{l}R \$ \\
1.800,00\end{array}$ \\
\hline 3 & $\begin{array}{l}\text { Criar plano de marketing Verde } \\
\text { divulgando as políticas e } \\
\text { estratégias de logística } \\
\text { reversa a ser implementadas. }\end{array}$ & mai/21 & $\begin{array}{l}\text { Ação } \\
\text { contínua }\end{array}$ & $\begin{array}{l}\mathrm{R} \$ \\
300,00 \\
\text { custo } \\
\text { mensal }\end{array}$ \\
\hline 4 & $\begin{array}{l}\text { Incluir no site da plataforma digital } \\
\text { as ações de marketing Verde e } \\
\text { consciência } \\
\text { Ecológica }\end{array}$ & jun/21 & $\begin{array}{l}\text { Ação } \\
\text { contínua }\end{array}$ & $\begin{array}{l}\mathrm{R} \$ \\
370,00 \\
\text { custo } \\
\text { mensal }\end{array}$ \\
\hline
\end{tabular}

RC: 84984

Disponível em: https://www.nucleodoconhecimento.com.br/administracao/marketing-verdeb 

políticas de

destinação de inservíveis

\subsubsection{ESTRUTURAR AS POLÍtICAS DE DESTINAÇÃO DE INSERVÍVEIS MANGUEIRAS E CONEXÕES USADAS}

O acúmulo de mangueiras e conexões inservíveis acarreta a ocupação de espaços que poderiam ser destinados a outras atividades da empresa e faz-se necessário uma atenção especial para o destino das mangueiras, evitando o depósito em locais inadequados ou impróprios. Sempre disponibilizando treinamentos para os colaboradores adotando medidas para diminuir os impactos ambientais no planeta, isso é mais que um ato de organização, um gesto de cidadania. Deste modo há vantagens na reutilização que irão desde o fator econômico, social, até o fator ambiental. É importante saber que ao destinar os bens inservíveis há riscos de se fazer tal procedimento se o mesmo for feito de modo incorreto.

Devido as mudanças nos direitos ao meio ambiente que ocorreram no Brasil desde meados da década de 90, surgiram normas e leis que visam dar proteção e condições de aproveitamento pelas gerações futuras do meio ambiente em condições saudáveis e necessárias para a sobrevivência.

Quadro 3. 5W2H - Estruturar as políticas de destinação de inservíveis mangueiras e conexões usadas

\section{Estruturar as políticas de destinação de inservíveis mangueiras e}

RC: 84984

Disponível em: https://www.nucleodoconhecimento.com.br/administracao/marketing-verdeb 
conexões usadas

O quê? Políticas de destinação de inservíveis

Por quê? Necessidade da conscientização a respeito do manejo dos resíduos

Onde? Casa das mangueiras

Quando? 20/04/2021, 13h às 17h

Quem? Todos os gestores

Como? Com planejamento e treinamento com os colaboradores

Quanto? $R \$ 2.000,00$

Fonte: Realizado pelos autores da pesquisa, 2021.

\subsubsection{DEFINIR ESTRATÉGIAS DE LOGÍSTICA REVERSA PARA ENVIO DOS PRODUTOS INSERVÍVEIS}

Verificou-se a necessidade de definir as estratégias de logística reversa um instrumento de desenvolvimento econômico e social na casa das mangueiras para reduzir o impacto negativo ocasionado pelo descarte incorreto e através do planejamento da distribuição do material descartado aumento da conscientização.

Quadro 4. 5W2H - Definir estratégias de logística reversa para envio dos produtos inservíveis

\section{Definir estratégias de logística reversa para envio dos produtos inservíveis}

O quê? Definir estratégias de logística reversa

Por quê? Reaproveitar os resíduos para que o meio ambiente seja preservado.

Onde? Casa das mangueiras

Quando? Primeira semana de Maio/2021

Quem? Todos os colaboradores

$\mathrm{RC}: 84984$

Disponível em: https://www.nucleodoconhecimento.com.br/administracao/marketing-verdeb 
Como? Focando nas atividades de planejamento e organização dos produtos.

Quanto? $\mathrm{R} \$ 1.800,00$

Fonte: Realizado pelos autores da pesquisa, 2021

\subsubsection{CRIAR PLANO DE MARKETING VERDE DIVULGANDO AS POLÍTICAS E ESTRATÉGIAS DE LOGÍSTICA REVERSA A SER IMPLEMENTADAS}

A implantação do marketing verde e logística reversa na casa das mangueiras pode trazer diversos benefícios como, por exemplo, reconhecimento, credibilidade, respeito ao meio ambiente e comprometimento com a melhoria do mundo onde vivemos. Além do melhor posicionamento no mercado, pois empresas com Marketing verde acabam chamando atenção de investidores melhorando seu posicionamento frente aos seus concorrentes.

A responsabilidade ambiental tem sido cada vez mais adotada pela sociedade em seus produtos e serviços. E em virtude disso, setores de produção e prestação de serviços são levados a propor medidas mais ecológicas em suas cadeias produtivas.

Segundo Xavier e Chiconatto (2013, p. 14) "marketing verde engloba todos os processos de um produto específico, desde o início e durante sua fabricação, preocupando-se também com as embalagens que gerará alterações na imagem de seu produto final, com isto propõe meios positivos a publicidade."

Quadro 5. 5W2H - Criar plano de marketing Verde divulgando as políticas e estratégias de logística reversa a ser implementadas

Criar plano de marketing Verde divulgando as políticas e estratégias de logística reversa a ser implementadas

RC: 84984

Disponível em: https://www.nucleodoconhecimento.com.br/administracao/marketing-verdeb 


\begin{tabular}{l|l}
\hline O quê? & Plano de Marketing verde \\
\hline Por quê? & Gerar bons resultados e resultar em benefícios ao meio ambiente \\
\hline Onde? & Casa das mangueiras \\
\hline Quando? & Primeira semana de maio 2021 \\
\hline Quem? & Todos os Gestores \\
\hline Como? & Com treinamentos voltados ao Marketing verde ação contínua \\
\hline Quanto? & $\mathrm{R} \$ 300,00$
\end{tabular}

Fonte: Realizado pelos autores da pesquisa, 2021

\subsubsection{INCLUIR NO SITE DA PLATAFORMA DIGITAL AS AÇÕES DE MARKETING VERDE E CONSCIÊNCIA ECOLÓGICA}

A comunicação deve aproveitar todas as ações sustentáveis realizadas na empresa para apresentar isso ao mercado e a divulgação também pode dar destaque para certificados ou ISO que garantam os aspectos ambientais. Pode usar vários meios para divulgação, como as redes sociais da empresa, o que favorece a divulgação além do ponto físico de comercialização. Por isso é fundamental que o marketing verde seja pautado em reais atitudes, e não somente um "discurso verde". O uso da internet em estratégias de marketing promove benefícios efetivos às empresas, posto que a primeira possui uma rede de abrangência mundial e, ainda, desperta interesses nos seus usuários.

Sendo assim, as plataformas digitais propiciam a ampliação do campo de atuação do marketing que, por sua vez, passa a contar não apenas com plataformas comuns para o consumidor, mas também com a internet e os dispositivos digitais no desenvolvimento das suas ações.

Quadro 6. 5W2H - Incluir no site da plataforma digital as ações de marketing Verde e consciência ecológica.

$\mathrm{RC}: 84984$

Disponível em: https://www.nucleodoconhecimento.com.br/administracao/marketing-verdeb 
Incluir no site da plataforma digital as ações de marketing Verde e consciência ecológica.

O quê? Site na Plataforma digital

Por quê? Vincula a marca a uma imagem ecologicamente consciente

Onde? Casa das mangueiras

Quando? Primeira semana de junho 2021

Quem? Gestores

Como? Divulgando no próprio site as ações e atitudes sustentáveis ação contínua

Quanto? $R \$ 370,00$

Fonte: Realizado pelos autores da pesquisa, 2021

\subsubsection{CAPACITAR A EQUIPE OPERACIONAL DA LOJA NO SENTIDO DE CUMPRIR AS POLÍTICAS DE DESTINAÇÃO DE INSERVÍVEIS}

A importância da capacitação dos colaboradores da casa das mangueiras, é que eles saibam que ao destinar os bens inservíveis há riscos de se fazer tal procedimento se o mesmo for feito de modo incorreto. Capacitar e orientar sobre as leis previstas na constituição como a Lei de Crimes Ambientais no 9605/1998 e a Política Nacional de Resíduos Sólidos lei oㅜ12.305/2010, há ainda as leis municipais e estaduais que conferem especificações quanto ao que em hipótese alguma deverá ser feito com os bens em inservibilidade.

Deixar claro para a equipe de colaboradores da casa das mangueiras, que todas estas discussões são tão somente para os materiais inservíveis e seu descarte, quanto para outros resíduos. Há algumas práticas na destinação de materiais inservíveis como, por exemplo, envolvendo óleo, papel entre outros materiais que pode ser de interesse do empreendimento em manter a frequência de atividades

RC: 84984

Disponível em: https://www.nucleodoconhecimento.com.br/administracao/marketing-verdeb 
para o descarte dos mesmos, uma vez que podem gerar benefícios de interesse do estabelecimento.

O acúmulo de resíduos ocorreu porque esta questão foi tratada por vários anos como uma consequência indesejada, mas inevitável, do desenvolvimento econômico, e sempre foi carente de regulação e fiscalização intensivas.

Quadro 7. 5W2H - Capacitar a equipe operacional da loja no sentido de cumprir as políticas de destinação de inservíveis

\section{Capacitar a equipe operacional da loja no sentido de cumprir as políticas} de destinação de inservíveis

O quê? Capacitar equipe operacional da loja

Por quê? Identificar os resíduos e adotar os procedimentos corretos.

Onde? Casa das mangueiras

Quando? 01 a $15 / 06 / 2021,08 \mathrm{hs}$ as $12 \mathrm{hhs}$

Quem? Gestores

Como? Com orientação nas palestras semanais

Quanto? $\quad \mathrm{R} \$ 2.000,00$

Fonte: Elaborado pelos autores da pesquisa, 2021.

\section{CONSIDERAÇÕES FINAIS}

A Revolução industrial mudou a forma de se consumir na sociedade ocidental, antes desse acontecimento, praticamente tudo o que era produzido era consumido, e, com a industrialização aumentou-se os produtos e em consequência a demanda por eles.Junto com a explosão do consumo, vieram as consequências dessa produção em larga escala que foram os impactos negativos ao meio ambiente. Logo, o desenvolvimento sustentável, trata de encontrar esse equilíbrio do uso correto dos

RC: 84984

Disponível em: https://www.nucleodoconhecimento.com.br/administracao/marketing-verdeb 
recursos naturais de uma forma que garanta condições ideais para as gerações futuras.

O marketing influencia as pessoas em relação a estimular o consumo e promover marcas. Essa ferramenta é relevante para as empresas como forma de se comunicar e mostrar aos seus consumidores os benefícios em se consumir determinados produtos e serviços, como é o caso do marketing verde, que dentre outras estratégias, consegue, na maioria dos casos, educar os consumidores acerca da importância da preservação ambiental. A Casa das Mangueiras é uma marca genuinamente amazonense que vem crescendo cada vez mais no ramo de materiais hidráulicos, com práticas alinhadas coma responsabilidade social e ambiental. Entre elas estão a diminuição do ciclo de produção das peças, a reciclagem dos produtos feitos de borracha e plástico e o correto processo de destinação de inservíveis, uso de água e energia, visando reduzir os impactos no meio ambiente.

A Empresa baseia-se na sustentabilidade em todos os seus processos e podemos perceber como a empresa os utiliza e mostra aos seus consumidores essas etapas, além de estar constantemente adquirindo produtos que tem essa preocupação sustentável. A Casa das Mangueiras consegue também captar clientes que se preocupam com o meio ambiente, trazendo o desejo de fazer isso de uma maneira mais consciente, pelosmétodos que a empresa utiliza tanto por meio da tecnologia limpa nos seus processos e produtos, como também na de comunicação como forma informação e fidelização de seus clientes. Para trabalhos futuros, fica a possibilidade de conhecer mais sobre a opinião e visão dos consumidores que compram na Casa das Mangueiras, entendendo se esses clientes percebem o marketing verde, e quais foram os motivos que os fizeram buscar conhecer a empresa e seus produtos.

RC: 84984

Disponível em: https://www.nucleodoconhecimento.com.br/administracao/marketing-verdeb 


\section{REFERÊNCIAS BIBLIOGRÁFICAS}

ABRELPE, 2017, Panorama dos Resíduos Sólidos no Brasil. Associação Brasileira das Empresas de Limpeza Pública e Resíduos Especiais. Disponível em http://abrelpe.org.br/download-panorama-2017/. Acessado em 05 de abril 2021.

ÁVILA, G. J.; ELY, L. Processos operacionais e resultados de empresas brasileiras após a certificação ambiental ISO 14001 [versão eletrônica]. Gestão \& Produção, 13(3), 475-48, 2016.

BANERJEE, S. et al. "Greenadvertising: salvation or oxymoron?" Journal of Advertising, Summer 1995: 7+. Academic OneFile. Web. 24 June 2012.

BELINK, A.; MATTAR, H. Pesquisa Akatu 2012. Rumo à Sociedade do BemEstar: Assimilação e Perspectivas do Consumo Consciente no Brasil Percepção da Responsabilidade Social Empresarial pelo Consumidor Brasileiro. São Paulo: Instituto Akatu, 2013. Disponível em: Acessado em 02 de dezembro de 2013.

BISPO, C. A. F., CAZARINI, E. W. Avaliação qualitativa paraconsistente do processo de implantação de um Sistema de Gestão Ambiental [versão eletrônica]. Gestão \& Produção, 13(1), 117-127, 2016.

CHURCHILL, G. A. J.; PETER, J. P. Marketing: criando valor para os clientes. 2. ed. São Paulo: Saraiva, 2015.

COLTRO, L.; DUARTE, L. C. Reciclagem de embalagens plásticas flexíveis: Contribuição da identificação correta. Polímeros [online]. 2013, vol.23, n.1, pp.128-134. Disponível em

http://www.scielo.br/scielo.php?script=sci_arttext\&pid=S0104-14282013000100022. Acessado em 11 de maio de 2019.

RC: 84984

Disponível em: https://www.nucleodoconhecimento.com.br/administracao/marketing-verdeb 
CSCMP. Council of Supply Chain Management Professionals. Acesso em: 5 de Abril de 2012.

FIORILLO, C. A. P. Curso de Direito Ambiental Brasileiro. Editora Saraiva. 14를 ed. São Paulo, 2013.

GALBIATI, A. F. O Gerenciamento Integrado de Resíduos Sólidos e a Reciclagem. 2012.

GARCIA, M. T. Comportamento do Consumidor. Rio de Janeiro: Gama Filho, 2012.

GUINDANI, R. A. Logística reversa. Curitiba: Instituto Federal do Paraná. Educação a Distância, 2012.

JUNIOR, O. G. G. Afinal, o que é marketing verde? Disponível em: https:/pt.linkedin.com/pulse/afinal-o-que-\%C3\%A9-marketing-verde-otto-guilhermegerstenberger-junior\&gt; Acesso em: 05 abril 2021.

LAS CASAS, A. L. Administração de marketing: conceitos, planejamento e aplicações à realidade brasileira. 4. reimpr. São Paulo: Atlas, 2013.

LIBÓRIO, D.; TERRA, L. Metodologia Cientifica. São Paulo: Rede Internacional de Universidades Laurete, 2015.

MAXIMIANO, A. C. A. Fundamentos de Administração: manual compacto para as disciplinas TGA a introdução à administração. 2. ed. - 4. reimpr. - São Paulo: Atlas, 2012. Disponível em: https://ucsvirtual.ucs.br/startservico/MIB/ Disponível em: 08 set. 2016.

MOORE, G. Promoção de Moda. São Paulo, SP: GG Moda, 2013. 
MOURA, N. G. Consumismo: você sabe o que é isso? - Politize!, Acesso em 05/04/2021.

OLIVEIRA NETO, G. C. O. et al. Avaliação das vantagens ambientais e econômicas da implantação da logística reversa no setor de vidros impressos. Ambiente e Sociedade, São Paulo, v. 17, n. 3, p. 199-220, 2014.

OTTMAN, J. A. As novas regras do Marketing Verde: estratégias, ferramentas e inspiração para o branding sustentável. São Paulo: M. Books do Brasil Editora Ltda. 2012.

PEREIRA, A. S. Metodologia da pesquisa científica [recurso eletrônico] 1. ed. Santa Maria, RS: UFSM, NTE, 2018.

SANTOS, J. G. A logística reversa como ferramenta para a sustentabilidade: um estudo sobre a importância das cooperativas de reciclagem na gestão dos resíduos sólidos urbanos. Belo Horizonte: Reuna, 2012.

TAVARES, F.; FERREIRA, G. G. T. Marketing verde: um olhar sobre as tensões entre greenwashing e eco propaganda na construção do apelo ecológico na comunicação publicitária. Revista Espaço Acadêmico, n. 138, nov. de 2012.

TRIGUEIRO, R. de M. Metodologia científica. Londrina: Editora e Distribuidora Educacional S.A., 2014.

VERGARA, S. C. Projetos e relatórios de pesquisa em administração. 16.ed.São Paulo: Atlas, 2016.

VILHENA, A. Guia da coleta seletiva de lixo/texto e coordenação. São Paulo: CEMPRE - Compromisso Empresarial para Reciclagem, 2013. 
XAVIER, R. N.; CHICONATTO, P. O Rumo do Marketing Verde nas Organizações: Conceito, Oportunidades e Limitações. Revista Capital Científico - Eletrônica (rcce), 2013.

ZANELLA, L. C. H. Metodologia de Pesquisa. 2.ed. reimp. - Florianópolis: Departamento de Ciências da administração/UFSC, 2013.

Enviado: Abril, 2021.

Aprovado: Maio, 2021. 